\title{
A Critical Role for the Nucleus Reuniens in Long-Term, But Not Short-Term Associative Recognition Memory Formation
}

\author{
Gareth R.I. Barker and ${ }^{-E}$ Elizabeth Clea Warburton \\ School of Physiology, Pharmacology and Neuroscience, University of Bristol, Bristol BS8 1TD, United Kingdom
}

Recognition memory for single items requires the perirhinal cortex (PRH), whereas recognition of an item and its associated location requires a functional interaction among the PRH, hippocampus (HPC), and medial prefrontal cortex (mPFC). Although the precise mechanisms through which these interactions are effected are unknown, the nucleus reuniens (NRe) has bidirectional connections with each regions and thus may play a role in recognition memory. Here we investigated, in male rats, whether specific manipulations of NRe function affected performance of recognition memory for single items, object location, or object-in-place associations. Permanent lesions in the NRe significantly impaired long-term, but not short-term, object-in-place associative recognition memory, whereas single item recognition memory and object location memory were unaffected. Temporary inactivation of the NRe during distinct phases of the object-in-place task revealed its importance in both the encoding and retrieval stages of long-term associative recognition memory. Infusions of specific receptor antagonists showed that encoding was dependent on muscarinic and nicotinic cholinergic neurotransmission, whereas NMDA receptor neurotransmission was not required. Finally, we found that long-term object-in-place memory required protein synthesis within the NRe. These data reveal a specific role for the NRe in long-term associative recognition memory through its interactions with the HPC and mPFC, but not the PRH. The delay-dependent involvement of the NRe suggests that it is not a simple relay station between brain regions, but, rather, during high mnemonic demand, facilitates interactions between the mPFC and HPC, a process that requires both cholinergic neurotransmission and protein synthesis.

Key words: acetylcholine; nucleus reuniens; object-in-place; protein synthesis; recognition memory

\section{Significance Statement}

Recognizing an object and its associated location, which is fundamental to our everyday memory, requires specific hippocampalcortical interactions, potentially facilitated by the nucleus reuniens (NRe) of the thalamus. However, the role of the NRe itself in associative recognition memory is unknown. Here, we reveal the crucial role of the NRe in encoding and retrieval of long-term object-in-place memory, but not for remembrance of an individual object or individual location and such involvement is cholinergic receptor and protein synthesis dependent. This is the first demonstration that the NRe is a key node within an associative recognition memory network and is not just a simple relay for information within the network. Rather, we argue, the NRe actively modulates information processing during long-term associative memory formation.

\section{Introduction}

Successful recognition memory depends upon networks of distributed brain regions, with the nature of to-be-remembered information determining which brain regions are recruited.

Received June 28, 2017; revised Oct. 30, 2017; accepted Nov. 29, 2017.

Author contributions: G.R.I.B. and E.C.W. designed research; G.R.I.B. and E.C.W. performed research; G.R.I.B. analyzed data; G.R.I.B. and E.C.W. wrote the paper.

This research was supported by the Biotechnology and Biological Sciences Research Council (Grant BB/L02134X/

1). We thank Jane Robbins for assistance with histology.

The authors declare no competing financial interests.

Correspondence should be addressed to Dr. E.C. Warburton, School of Physiology, Pharmacology and Neuroscience, University of Bristol, Biomedical Sciences Building, University Walk, Bristol BS8 1TD, UK. E-mail: e.c.warburton@bristol.ac.uk.

DOI:10.1523/JNEUROSCI.1802-17.2017

Copyright $\odot 2018$ the authors $\quad 0270-6474 / 18 / 383208-10 \$ 15.00 / 0$
Therefore, recognition of single items or objects depends on the perirhinal cortex (PRH) (Ennaceur et al., 1996; Bussey et al., 1999; Wan et al., 1999; Diana et al., 2007; Albasser et al., 2010; Kim, 2011, 2013), whereas recognition of an object and its associated spatial information (object-in-place memory) requires the PRH (Bussey et al., 2001; Barker et al., 2007; Bachevalier and Nemanic, 2008), hippocampus (HPC), and prefrontal cortex (PFC) (Kesner and Ragozzino, 2003; Browning et al., 2005; Barker et al., 2007, 2017; Barker and Warburton, 2008; Brincat and Miller, 2015). Importantly, during object-in-place memory, these three brain regions appear to operate cooperatively, forming an associative recognition memory network (Barker et al., 2007, Barker and Warburton, 2011). However, because these regions are connected by both direct and indirect anatomical pathways, the pre- 
cise routes by which these neural interactions are affected are largely unknown. One brain region, the nucleus reuniens of the thalamus (NRe), has reciprocal connections with the PRH (Agster et al., 2016; Tomás Pereira et al., 2016) medial PFC (mPFC) (Vertes, 2002; Vertes et al., 2006; Hoover and Vertes, 2012), and HPC (Herkenham, 1978; Wouterlood et al., 1990; Dolleman-Van der Weel and Witter, 1996; Vertes et al., 2006). In addition, a proportion of NRe neurons project to both mPFC and HPC, so NRe may simultaneously influence both HPC and mPFC processing (Hoover and Vertes, 2012) and provide a route through which these three brain regions may interact.

There is evidence that the NRe plays a specific role in memory processing under certain conditions. Permanent or temporary inactivation of the ventral midline thalamic nuclei (i.e., NRe and neighboring rhomboid nucleus, $\mathrm{Rh}$ ) impaired a spatial win-shift task (Hembrook and Mair, 2011), a spatial strategy shifting task (Cholivin et al., 2013), and a delayed nonmatching to position (Hembrook et al., 2012) task, although such lesions had no effect on simple spatial learning (but see Dolleman-Van der Weel et al., 2009). NRe disruption was also found to impair long-term, but not short-term, spatial memory (Loureiro et al., 2012). Therefore, the NRe plays a key role in spatial memory processing either when the demands on the HPC are high or interactions between the HPC and $\mathrm{mPFC}$ are required. Whether the NRe participates in PRH-dependent tasks has not, to our knowledge, been investigated.

In the present study, we hypothesized that the NRe will have a key role in recognition memory formation through interactions with the PRH, mPFC, or HPC. To test this hypothesis, we examined the effects of specific manipulations of the NRe on a series of object recognition memory tasks. We investigated the following: (1) the necessity of the NRe for single item and associative recognition memory using permanent lesions placed in the midline thalamus; (2) the necessity of the NRe separately during encoding and retrieval; (3) the role of NMDA receptor (NMDAR) and cholinergic neurotransmission in the NRe for object-in-place encoding; and (4) whether long-term memory maintenance was dependent on protein synthesis in the NRe.

\section{Materials and Methods}

\section{Subjects}

Experiment 1 used 20 male rats and Experiments 2-5 used a single cohort of 12 male rats (Lister hooded strain; Harlan Laboratories) weighing $300-350 \mathrm{~g}$ at the start of the experiments. All animals were housed in groups of four, under a $12 \mathrm{~h}$ light/dark cycle (light phase, 6.00 P.M. to 6.00 A.M) with ad libitum access to food and water. Behavioral testing was conducted during the dark phase of this cycle. All animal procedures were performed in accordance with United Kingdom Animals Scientific Procedures Act (1986) and associated guidelines. All efforts were made to minimize any suffering and the number of animals used.

\section{Surgical procedure}

Bilateral excitotoxic lesion of the ventral midline nuclei (NRe/Rh) (Experiment 1). Before surgery, all rats were anesthetized (isoflurane: induction $4 \%$; maintenance $2-4 \%$ ) and placed in a stereotaxic frame with the incisor bar set so as to achieve flat skull. The scalp was further anesthetized using lidocaine, cut, and retracted. After craniotomy, excitotoxic lesions to the target region was made using NMDA dissolved in phosphate buffer and injected through a $1 \mu \mathrm{l}$ Hamilton syringe at the following coordinates relative to bregma: anterior-posterior (AP) $-1.72 \mathrm{~mm}$ and -2.40 $\mathrm{mm}$, mediolateral (ML) $\pm 0.2 \mathrm{~mm}$, and dorsoventral (DV) $-7.40 \mathrm{~mm}$ for both AP coordinates. NMDA $(0.1 \mu \mathrm{l}$ and $0.09 \mathrm{M})$ was injected gradually over $4 \mathrm{~min}$ and the needle left in situ for a further $4 \mathrm{~min}$. For the sham surgeries, the animals underwent the same surgical procedures as the lesion group with the exception that no excitotoxin was injected once the needle had been lowered ( $n=10$ for all groups).
Once surgery was completed, the skin was sutured and an antibiotic powder (Acramide: Dales Pharmaceuticals) applied. All animals received at least $5 \mathrm{ml}$ of glucose saline subcutaneously and systemic analgesia intramuscularly ( $0.05 \mathrm{ml}$ of Vetegesic; Reckitt Benckiser) before the end of surgery. Hypromellose eye drops (Tubilux Pharma) were given at the beginning and end of surgery. Animals recovered for at least $14 \mathrm{~d}$ before habituation to the behavioral arena commenced.

Cannulae implantation in the NRe (Experiments 2-5). After induction of anesthesia as described above, rats were implanted with a single cannula aimed at the NRe. The stainless steel guide cannula (26 gauge; Plastics One) was implanted through a burr holes in the skull at the following coordinates relative to skull at bregma: $\mathrm{AP}-2.3 \mathrm{~mm}, \mathrm{ML} \pm 1.7 \mathrm{~mm}$, and DV $-6.2 \mathrm{~mm}$ (relative to surface of the skull) with the manipulator arm at an angle of $15^{\circ}$ to the vertical (coordinates based on Cholvin et al., 2013). The cannula was anchored to the skull by stainless steel skull screws (Plastics One) and dental acrylic. After surgery, each animal was given fluid replacement therapy and analgesia as described above and were housed individually for $7 \mathrm{~d}$ to recover from surgery and in pairs thereafter. The animals recovered for at least $14 \mathrm{~d}$ before habituation to the testing arena began. Between infusions, 33 gauge obdurators (Plastics One) were used to keep the cannula patent.

\section{Histology}

On completion of the behavioral tasks, animals were killed by transcardial perfusion with phosphate buffer (PB) followed by $4 \%$ paraformaldehyde (PFA). The brains were postfixed in $4 \%$ PFA for a minimum of $24 \mathrm{~h}$, followed by $48 \mathrm{~h}$ in $30 \%$ sucrose in PB. Coronal sections $(40 \mu \mathrm{m})$ were cut on a cryostat and the sections mounted directly onto gelatincoated slides, stained using cresyl violet, and coverslipped using DPX mounting medium. Slides were then viewed under a light microscope and the extent of lesion or location of the cannula recorded.

To assess the extent of the $\mathrm{Ne} / \mathrm{Rh}$ lesion representative sections along the AP axis, the following coordinates relative to bregma were selected: $-1.53 \mathrm{~mm},-2.00 \mathrm{~mm},-2.45 \mathrm{~mm},-2.85 \mathrm{~mm}$, and $-3.25 \mathrm{~mm}$. For each section, the area of each ventral midline thalamic nuclei was measured using ImageJ and the measured areas across the sections were summed for each nuclei to generate a total area for each nuclei. Lesion size (\% lesion) was calculated for each thalamic nucleus in each animal in the lesion group by comparison with the mean nuclei area in the sham group.

To assess the position of the cannula, sections along the AP axis of each rat brain between $-1.8 \mathrm{~mm}$ and $-2.5 \mathrm{~mm}$ (relative to bregma) were selected and compared with those in the rat brain atlas (Swanson, 1998).

\section{Behavioral apparatus}

Behavioral testing took place in a wooden, open-topped arena $(50 \mathrm{~cm}$ high, $90 \mathrm{~cm}$ wide, and $100 \mathrm{~cm}$ long) with gray walls and external black curtains to a height of $1.5 \mathrm{~m}$ to restrict distal cues. The floor which was covered in sawdust in all experiments (unless stated otherwise) was cleaned between animals. Exploration was monitored using an overhead camera and recorded onto DVD. The amount of object exploration was determined using in-house counting software on a computer within the room. Objects were constructed from Duplo (Lego UK) and varied in color and size from $9 \times 8 \times 7 \mathrm{~cm}$ to $25 \times 15 \times 10 \mathrm{~cm}$, and were too heavy to displace. New objects were used for every experiment.

\section{Behavioral procedures}

Habituation. After being handled for a week, the animals were habituated to the arena without stimuli for 10-15 min daily for $4 \mathrm{~d}$ before the commencement of the behavioral testing, the animals were also habituated to the infusion procedure.

Object-in-place task. This task comprised a sample and test phases separated by a delay, the length of which depended on the experiment. In the sample phase, each subject was presented with four different objects (objects A-D). These objects were placed in the corners of the arena $10 \mathrm{~cm}$ from the walls (Fig. $1 A$ ). In this experiment, one of the walls of the arena was black in color, whereas the other three were gray, and the curtains were partially removed from around the arena to provide additional extramaze cues. Each subject was placed in the center of the arena and allowed to explore the objects for $5 \mathrm{~min}$. During the delay period (which varied depending on the experiment or drug infused, see Results 
A

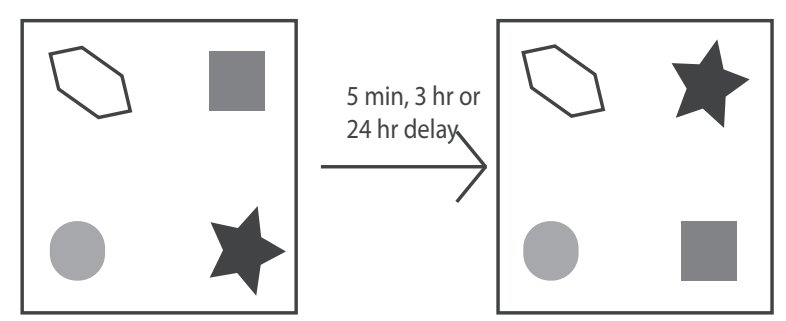

B

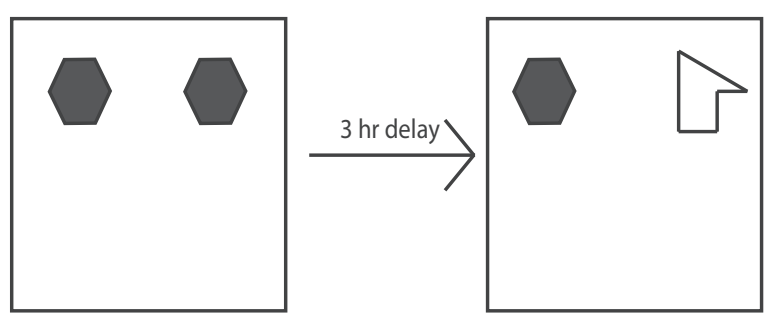

C

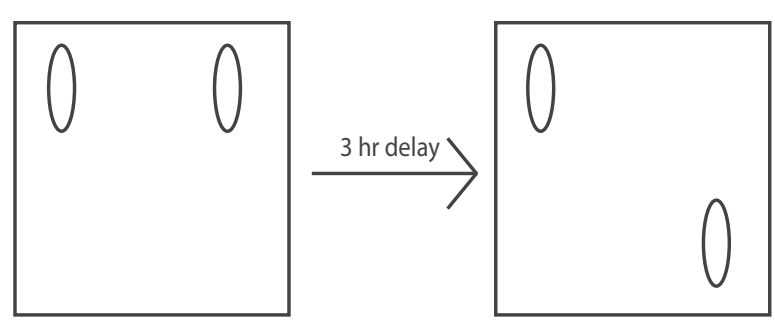

Figure 1. Diagram of the spontaneous object recognition tasks. $A$, Object-in-place task. $B$, Novel object recognition task. C, Object location task.

for details), objects were cleaned with alcohol to remove olfactory cues and any sawdust that had stuck to the object. In the test phase, two of the objects; for example, objects B and D (which were both on the left or right of the arena), exchanged positions (see Fig. $1 A$ ) and the subject was allowed to explore the objects for $3 \mathrm{~min}$. The time spent exploring the two objects that had changed position was compared with the time spent exploring the two objects that had remained in the same position. The objects moved (i.e., those on the left or right) and the position of the objects in the sample phase were counterbalanced between rats. If objectin-place memory is intact, then the subject will spend more time exploring the two objects that are in different locations compared with the two objects that are in the same locations.

Object location task. Object location testing was conducted with the arena in the same configuration as for the object-in-place task (i.e., three gray-colored walls and one black wall and the curtain around the maze was partially removed to provide the animals with access to extramaze cues). In the sample phase, animals were allowed to explore 2 identical copies of an object for $4 \mathrm{~min}$ before being removed from the arena for the $3 \mathrm{~h}$ delay period. After the delay, the animals were placed back into the arena, which now contained two objects identical to those used in the sample phase (Fig. 1B). One object was replaced in the location previously occupied by a sample phase object, but the other object was placed in a new location within the arena. Object exploration was recorded for 3 min. The position of the moved object was counterbalanced across rats. If memory for the objects' original location is intact, then animals will spend longer exploring the object in the novel location.

Novel object preference task. The novel object preference procedure comprised a sample and test phases separated by a delay. In the sample phase, duplicate copies of an object (e.g., objects A1 and A2) were placed near the two corners at either end of one side of the arena (Fig. 1C). The animal was placed into the arena facing the center of the opposite wall and allowed a total of either $40 \mathrm{~s}$ of exploration of A1 and A2 or 4 min in the arena. The retention delay varied depending upon the experiment (see Results). At test time (3 min duration), the animal was replaced in the arena and presented with two objects using the same positions as at acquisition; one object (A3) was the third copy of the object used in the sample phase and the other was a novel object (B3). The positions of the objects in the test and the objects used as novel or familiar were counterbalanced between the animals. If memory for the object encountered in the sample phase is intact, then animals will spend longer exploring the novel compared with the familiar object.

\section{Drug infusions}

General procedures followed Barker et al. (2008). The drugs used were as follows: muscimol, 2-amino-5-phosphonopentanoic acid (AP5; Tocris Bioscience), scopolamine hydrobromide (Sigma-Aldrich), mecamylamine, anisomycin (Abcam), and actinomycin D (Tocris Bioscience). Muscimol, AP5, scopolamine, and mecamylamine were dissolved in sterile $0.9 \%$ saline solution. Anisomycin was dissolved in equimolar hydrogen chloride and the $\mathrm{pH}$ was corrected to 7.4 with sodium hydroxide. Actinomycin D was dissolved in DMSO at a concentration of $50 \mathrm{~mm}$ and diluted using sterile $0.9 \%$ saline to the infusion concentration of $50 \mu \mathrm{M}$, thus the concentration of DMSO infused was $0.1 \%$. Vehicle infusions consisted of sterile $0.9 \%$ saline or saline plus $0.1 \%$ DMSO (actinomycin D). Muscimol was infused at a concentration of $2.4 \mathrm{mM}$, AP5 at $25 \mathrm{~mm}$, scopolamine at $26 \mathrm{~mm}$, mecamylamine at $50 \mu \mathrm{M}$, anisomycin at $47 \mathrm{~mm}$, and actinomycin D at $50 \mu \mathrm{M}$.

Infusions were made through a 33 gauge cannula (Plastics One) inserted into the implanted guide cannulae and extending $1 \mathrm{~mm}$ beyond the end of the guide cannula and attached to a $5 \mu$ l Hamilton syringe via polyethylene tubing. A volume of $0.3 \mu \mathrm{l}$ of fluid was injected into the NRe over a 1 min period. All intracerebral injections were made by infusion pump (Harvard Bioscience). To examine effects of manipulations on encoding, the infusions were made before the sample phase; to determine the effects of manipulations on retrieval, infusions were made before the test phase. After the infusion period, the infusion cannula remained in place for a further $5 \mathrm{~min}$ before being removed. The animal was placed in the arena and the sample or test phase began 9 min later; that is, $15 \mathrm{~min}$ after the start of the infusion. The time points for microinjection were based on reports that muscimol (at a higher concentration and volume than was used in the present study) takes effect within minutes and neuronal activity, with the exception of those neurons at the center of the injection, will have recovered within 3-3.5 h (Arikan et al., 2002; van Duuren et al., 2007)

\section{Experimental design and statistical analysis}

In Experiment 1, 20 animals were randomly assigned into the sham $(n=$ $10)$ or NRe/Rh lesion groups $(n=10)$. In Experiments $2-5,12$ animals received bilateral infusions of drug or vehicle using a crossover design and each animal was retested after a minimum rest period of $48 \mathrm{~h}$. Therefore, each animal served as its own control. Cannula blockage resulted in the occasional loss of an animal (indicated by reduced degrees of freedom in the quoted statistical tests). Analysis of data from previous experiments in our laboratory indicated that a sample size of 8 will give a power of 0.8. Larger sample sizes were used to ensure that statistical power was maintained if animals were lost from the analysis.

All measures of exploration were made with the experimenter blinded to the lesion or drug status of each animal. Exploratory behavior was defined as the animal directing its nose toward the object at a distance of $<2 \mathrm{~cm}$. Any other behavior, such as looking around while sitting on or resting against the object, was not considered as exploration. Discrimination between the objects was determined using a discrimination ratio (DR), which was calculated as the difference in time spent by each animal exploring the novel object, objects in novel configuration, or object in novel location compared with the familiar object/familiar configuration or familiar location divided by the total time spent exploring all objects. This measure therefore takes into account individual differences in the total amount of exploration between rats (Ennaceur and Delacour, 1988; Dix and Aggleton, 1999). Comparisons of DR were made using a multifactor ANOVA followed by simple main effects analysis. The variables lesion (Experiment 1), delay (Experiment 1,2, 3, and 5), and infusion timing (Experiment 4) were treated as between-subjects factors drug, whereas drug (Experiments 2-5) was treated as a within-subjects fac- 

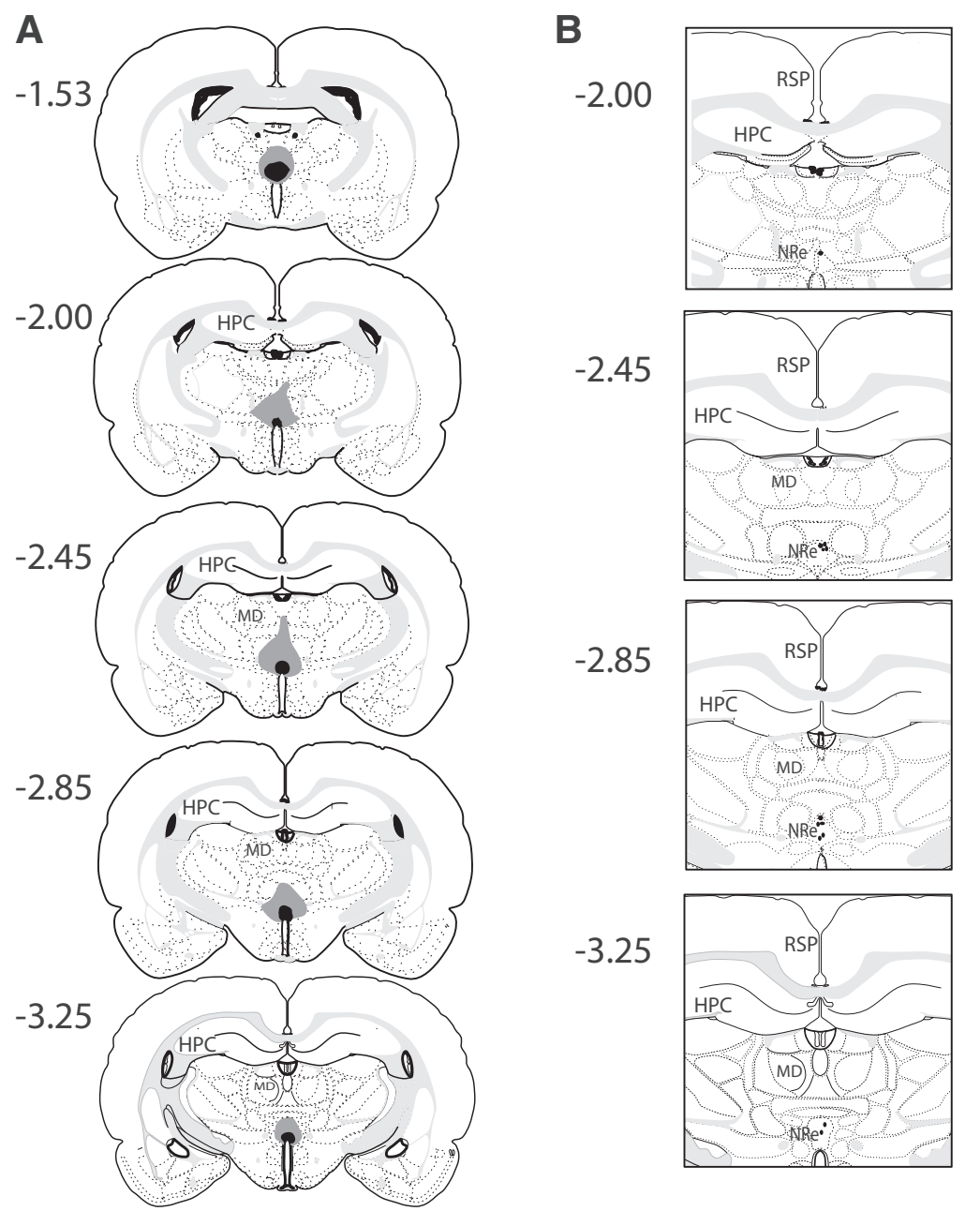

$-2.45$

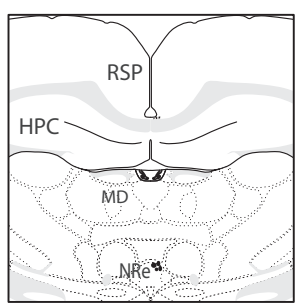

$-2.85$

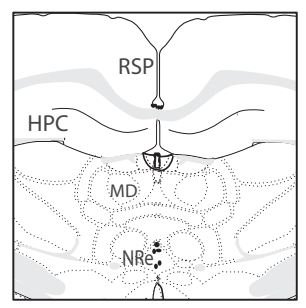

$-3.25$

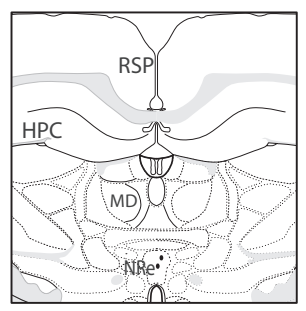

Figure 2. A, Diagrammatic reconstructions showing the cases with the largest (gray) and smallest (black) lesions in the ventral midline thalamic nuclei including the NRe and Rh. $\boldsymbol{B}$, Diagrammatic representation of the induvial infusion sites in the NRe in each animal. The numbers correspond to the approximate position relative to bregma (Swanson, 1998). RSP, Retrosplenial cortex; MD, medial dorsal thalamic nuclei.

tor. Additional analyses in both experiments investigated whether individual groups had discriminated between the objects using a onesample $t$ test (two-tailed) comparing the DR against chance performance $(\mathrm{DR}=0)$. All statistical analyses were performed using SPSS.

\section{Results}

\section{Histology}

Experiment 1

One lesion and one sham animal died postoperatively; therefore, $n=9$ for each condition for all experiments. Histological analysis revealed that all remaining animals had substantial cell loss within the NRe and Rh. The largest and smallest of the lesions is shown in Figure $2 A$. The greatest tissue loss within the ventral midline nuclei was found in the NRe (mean \pm SEM, $72 \pm 5.6 \%$, $\max 93 \%$, $\min 41 \%$ ), whereas the $\mathrm{Rh}$ and perireuniens nuclei sustained less damage (Rh: $33 \pm 6.3 \%$, max $64 \%$, min $4 \%$; perireuniens $28 \pm 7.3 \mathrm{~T}, \max 72 \%$, min $0 \%$ ). Comparison of the damage across the AP extent of the lesion revealed significant cell loss in the anterior regions (Fig. $2 \mathrm{~A}$ ). Therefore, at $2.0 \mathrm{~mm}$ posterior to bregma, the mean cell loss was as follows NRe: $88 \pm 6.7 \%$, Rh: $58 \pm 10.2 \%$, and perireuniens nuclei: $43 \pm 11.8 \%$. At $3.25 \mathrm{~mm}$ posterior to bregma, the mean cell loss in NRe was $43 \pm 7.3 \%$, Rh $10 \pm 4.7 \%$, and perireuniens $1.4 \pm 4.9 \%$.
Outside of the NRe and $\mathrm{Rh}$, there was limited cell loss in other thalamic nuclei. Two cases sustained damage in the submedial nucleus (SMT) (cell loss of 59\% and $55 \%$ ), whereas in all other cases, the cell loss in SMT was more restricted (>30\%). Additional cell loss occurred in the anteromedial nucleus, mediodorsal nucleus, paraventricular nucleus, central medial nucleus, zona incerta, ventral medial nucleus, and paracentral nucleus, although in all cases, the cell loss was $<10 \%$ of the structure.

\section{Experiments 2-5}

Histological examination confirmed that the tips of the cannulae were in the NRe, as shown in Figure $2 B$.

\section{Experiment 1: Lesions in the NRe/Rh impair long-term associative recognition memory, but are without effect on single item recognition or spatial discrimination}

The effect of lesions in the NRe/Rh on object-in-place memory was tested after a 5 min or $3 \mathrm{~h}$ delay and on object recognition and object location tasks after a $3 \mathrm{~h}$ delay. The performance of the sham and $\mathrm{NRe} / \mathrm{Rh}$ groups are shown in Figure 3. Performance in the object-in-place task (Fig. 3A) was significantly impaired in the $\mathrm{NRe} / \mathrm{Rh}$ lesion group in a delaydependent manner. ANOVA revealed a significant lesion $\times$ delay interaction $\left(F_{(1,33)}=17.76, p=0.000\right)$ and a significant main effect of delay $\left(F_{(1,33)}=19.71\right.$, $p=0.000)$. There was no significant main effect of lesion $\left(F_{(1,33)}=3.89, p=0.057\right.$ n.s.). Analysis of the simple main effects confirmed that performance of the NRe/Rh group was significantly worse than the sham group at the $3 \mathrm{~h}$ retention delay $(p=0.0005)$. Comparison of the groups' performance against chance revealed that the sham group showed significant discrimination between the moved and unmoved objects at both delays ( 5 min delay: $t_{(8)}=4.69 ; p=$ 0.002 ; 3 h delay: $\left.t_{(8)}=4.39, p=0.002\right)$. In contrast, the NRe/Rh lesion group showed significant discrimination after the $5 \mathrm{~min}$ delay $\left(t_{(9)}=11.06, p=0.000\right)$, but not the $3 \mathrm{~h}$ delay $\left(t_{(8)}=-0.93\right.$, $p=0.380$ n.s. $)$.

Performance of the sham and NRe/Rh groups in the object recognition and object location memory tasks was determined with a $3 \mathrm{~h}$ delay between sample and test because the NRe/Rh group showed impaired object-in-place performance after this delay. There was no difference between the two groups in object recognition performance (Fig. 3B), main effect of lesion $\left(F_{(1,16)}=0.44, p=\right.$ 0.517 n.s.), or object location memory performance (Fig. $3 B$; main effect of lesion $F_{(1,16)}=0.06, p=0.805$ n.s.). Further, both groups demonstrated significant discrimination between the novel and familiar in the object recognition task $\left(\operatorname{sham} t_{(8)}=9.51, p=0.000\right.$; $\left.\mathrm{NRe} / \mathrm{Rh} t_{(8)}=5.15, p=0.001\right)$ and object location task $\left(\operatorname{sham} t_{(8)}=\right.$ $\left.5.06, p=0.001 ; \mathrm{NRe} / \mathrm{Rh} t_{(8)}=11.638, p=0.000\right)$.

Total object exploration levels in the sample and test phases of each of the tasks did not differ between the sham and NRe/Rh 
a
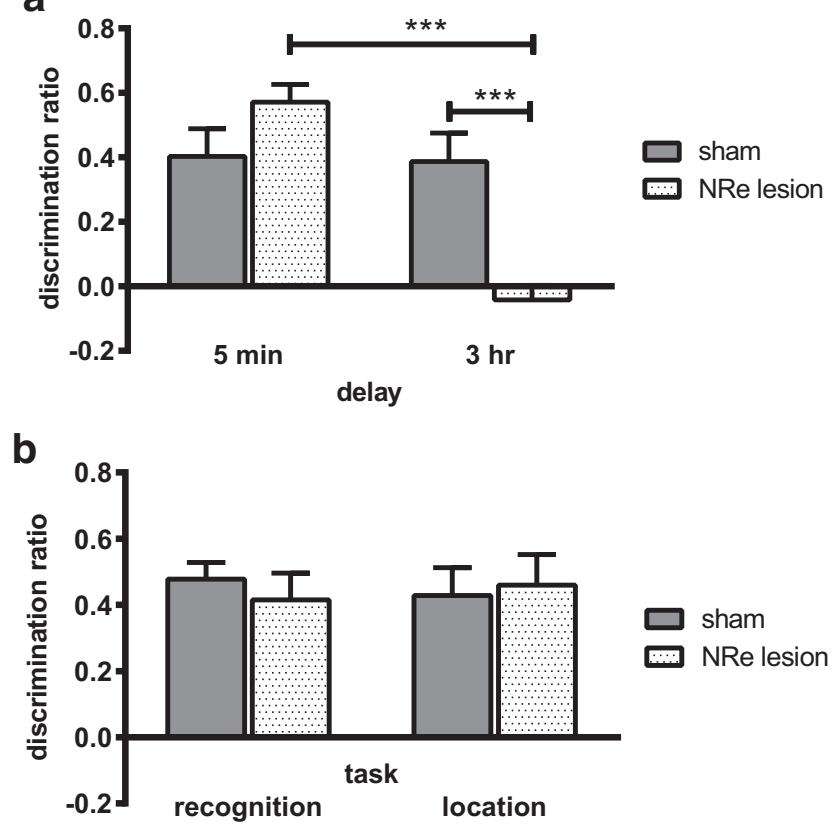

Figure 3. Lesions of the NRe/Rh impair the formation of long-term associative recognition memories. $\boldsymbol{A}$, Performance in the object-in-place task was significantly impaired when memory was tested at a 3 h delay, but not when memory was tested at a 5 min delay. $\boldsymbol{B}$, Non-associative recognition memory was not altered by lesion of the NRe/Rh. Data are shown as mean $\pm \mathrm{SEM}$. $n=9$ for all. ${ }^{* * *} p<0.001$.

groups (Table 1). Analysis of the sample phase exploration during the object-in-place task revealed no significant lesion $\times$ delay interaction $\left(F_{(1,33)}=0.03, p=0.876\right.$ n.s. $)$, main effect of lesion $\left(F_{(1,33)}=1.22, p=0.278\right.$ n.s. $)$, or delay $\left(F_{(1,33)}=3.35, p=0.076\right.$ n.s.). Analysis of test phase exploration revealed no significant lesion $\times$ delay interaction $\left(F_{(1,33)}=0.08, p=0.776\right.$ n.s. $)$ and no significant main effect of lesion $\left(F_{(1,33)}=1.16, p=0.289\right.$ n.s.); however, there was a significant main effect of delay $\left(F_{(1,33)}=\right.$ $4.48, p=0.042$ ) accounted for by an increase in object exploration in both conditions at the $3 \mathrm{~h}$ delay.

ANOVA of the total object exploration completed in either the object recognition and object location tasks revealed no significant differences in either the sample phase (object recognition: $F_{(1,16)}=0.29, p=0.866$ n.s.; object location: $F_{(1,16)}=1.90$, $p=0.187$ n.s.) or test phase (object recognition: $F_{(1,16)}=0.53$, $p=0.478$ n.s.; object location: $F_{(1,16)}=0.58, p=0.458$ n.s.).

Therefore, these data suggest that the midline thalamic nuclei, which include the NRe, are critical for object-in-place associative recognition memory performance after a $3 \mathrm{~h}$, but not a $5 \mathrm{~min}$, retention delay.

\section{Experiment 2: Muscimol inactivation of the NRe impaired both encoding and retrieval of long-term associative recognition memory}

We next investigated whether temporary inactivation of the NRe disrupted either encoding or retrieval of object-in-place recognition memory. Infusions (1 min duration) occurred either $15 \mathrm{~min}$ before the sample phase to inactivate the NRe during encoding or $15 \mathrm{~min}$ before the test phase to inactivate the NRe during retrieval. The effect of muscimol on encoding object-in-place memory was tested after a 5 min or $3 \mathrm{~h}$ delay; the effect of muscimol on retrieval was tested after a $3 \mathrm{~h}$ delay only.
Presample phase infusion of muscimol into the NRe produced a delay-dependent deficit in object-in-place memory (Fig. 4), which was confirmed by a significant drug $\times$ delay interaction $\left(F_{(1,22)}=6.02, p=0.023\right)$ and main effect of delay $\left(F_{(1,22)}=7.87\right.$, $p=0.010)$, but no significant main effect of drug $\left(F_{(1,22)}=4.15\right.$, $p=0.054$ n.s.). Analysis of the simple main effects revealed a significant difference between the muscimol- and vehicle-infused animals at the $3 \mathrm{~h}$ delay only $(p=0.000)$. Comparison of the groups' discrimination performance against chance revealed that the vehicle and muscimol animals discriminated significantly between the moved and unmoved objects at the 5 min delay (vehicle: $t_{(11)}=5.62, p=0.000$; muscimol: $t_{(11)}=5.50, p=0.000$ ), but not at the 3 h delay (vehicle: $t_{(11)}=6.12, p=0.000$; muscimol: $t_{(11)}=0.79, p=0.446$ n.s. $)$.

Pretest infusion of muscimol significantly impaired object-inplace performance (Fig. 4; main effect of drug $F_{(1,11)}=51.42$, $p=0.000$ ), which was confirmed by comparison of each group's performance against chance, revealing that vehicle-infused $\left(t_{(11)}=\right.$ 7.10, $p=0.000)$, but not muscimol-infused $\left(t_{(11)}=-0.90, p=\right.$ 0.389 n.s.), animals showed significant discrimination.

Analysis of the total object exploration completed in the sample and test phases of the object-in-place task revealed no significant differences between the muscimol- and vehicle-treated groups (for means, see Table 2). ANOVA of the total object exploration in the test phase after pretest phase infusions revealed no significant drug $\times$ delay interaction $\left(F_{(1,22)}=2.73, p=0.113\right.$ n.s.) or main effect of $\operatorname{drug}\left(F_{(1,22)}=0.20, p=0.663\right.$ n.s. $)$, but there was a significant main effect of delay $\left(F_{(1,22)}=14.70, p=\right.$ $0.001)$ because there was an increase in total object exploration after the $3 \mathrm{~h}$ delay in both groups.

Therefore, both the encoding and retrieval of long-term objectin-place associative recognition memory is dependent on neuronal activation with the NRe.

\section{Experiment 3: NMDAR transmission in the NRe is not} required for long-term associative recognition memory To determine whether object-in-place memory encoding is dependent on NMDAR neurotransmission in the NRe, the NMDAR antagonist AP5 was infused into the NRe before the sample phase and memory performance was assessed after a 3 or 24 h delay.

Infusion of AP5 into the NRe before the sample phase had no effect on object-in-place performance at either retention delay (Fig. 5). Two-way ANOVA with drug and delay as factors found no significant interaction $\left(F_{(1,22)}=0.001, p=0.984\right.$ n.s. $)$ and no significant main effect of drug $\left(F_{(1,22)}=1.27, p=0.273\right.$ n.s. $)$ or delay $\left(F_{(1,22)}=0.17, p=0.688\right.$ n.s.). Further analysis confirmed that both groups significantly discriminated after the $3 \mathrm{~h}$ (vehicle $t_{(11)}=6.64$, $\left.p=0.001 ; \mathrm{AP}_{(11)}=6.53, p=0.001\right)$ and $24 \mathrm{~h}\left(\right.$ vehicle $_{(11)}=6.49$, $p=0.001$; AP5 $\left.t_{(11)}=5.31, p=0.001\right)$ retention delays.

AP5 did not significantly alter total object exploration levels in either the sample or test phase (for means, see Table 2). Analysis of sample phase exploration revealed no significant drug $\times$ delay interaction $\left(F_{(1,22)}=0.42, p=0.524\right.$ n.s. $)$ and no significant main effect of drug $\left(F_{(1,22)}=0.25, p=0.620\right.$ n.s. $)$ or delay $\left(F_{(1,22)}=\right.$ $0.70, p=0.410$ n.s. $)$. Analysis of the total test phase object exploration revealed no significant drug $\times$ delay interaction $\left(F_{(1,22)}=\right.$ $0.18, p=0.679$ n.s. $)$ and no significant main effect of $\operatorname{drug}\left(F_{(1,22)}=\right.$ $0.01, p=0.911$ n.s. $)$ or delay $\left(F_{(1,22)}=2.93, p=0.101\right.$ n.s. $)$.

These results show that NMDAR activation in the NRe is not required for associative recognition memory encoding. 
Table 1. Mean exploration times ( \pm SEM) in the sample and test phases of the spontaneous object exploration tasks in the NRe/Rh lesion and sham groups

\begin{tabular}{|c|c|c|c|c|c|c|c|}
\hline \multirow[b]{2}{*}{ Task } & \multirow[b]{2}{*}{ Delay } & \multirow[b]{2}{*}{ Condition } & \multirow{2}{*}{$\begin{array}{l}\text { Duration of } \\
\text { sample phase (s) }\end{array}$} & \multirow{2}{*}{$\begin{array}{l}\text { Exploration in } \\
\text { sample phase (s) }\end{array}$} & \multicolumn{3}{|c|}{ Exploration in test phase (s) } \\
\hline & & & & & Novel & Familiar & Total \\
\hline \multirow[t]{4}{*}{ Object-in-place } & \multirow[t]{2}{*}{$5 \mathrm{~min}$} & Sham & 300.0 & $97.0 \pm 2.9$ & $25.4 \pm 2.5$ & $9.8 \pm 1.0$ & $35.2 \pm 2.8$ \\
\hline & & Lesion & 300.0 & $104.1 \pm 4.6$ & $29.6 \pm 3.0$ & $8.4 \pm 1.3$ & $38.1 \pm 3.6$ \\
\hline & \multirow[t]{2}{*}{$3 \mathrm{~h}$} & Sham & 300.0 & $87.6 \pm 7.3$ & $29.2 \pm 3.1$ & $12.6 \pm 1.8$ & $41.8 \pm 3.7$ \\
\hline & & Lesion & 300.0 & $92.9 \pm 4.7$ & $22.4 \pm 1.3$ & $24.4 \pm 1.4$ & $46.8 \pm 1.9$ \\
\hline \multirow[t]{2}{*}{ Object recognition } & \multirow[t]{2}{*}{$3 \mathrm{~h}$} & Sham & $121.4 \pm 9.0$ & 40.0 & $24.7 \pm 2.5$ & $8.0 \pm 0.6$ & $32.7 \pm 2.8$ \\
\hline & & Lesion & $118.9 \pm 8.2$ & 40.0 & $25.9 \pm 2.4$ & $9.9 \pm 0.9$ & $35.8 \pm 2.1$ \\
\hline \multirow[t]{2}{*}{ Object location } & \multirow[t]{2}{*}{$3 \mathrm{~h}$} & Sham & 240.0 & $52.6 \pm 4.6$ & $20.2 \pm 2.5$ & $7.5 \pm 0.9$ & $27.7 \pm 2.9$ \\
\hline & & Lesion & 240.0 & $62.6 \pm 5.1$ & $18.3 \pm 2.3$ & $6.4 \pm 0.9$ & $24.6 \pm 2.5$ \\
\hline
\end{tabular}

Exploration in the test phase is presented as mean time spent exploring the novel and familiar objects separately a and as total exploration.

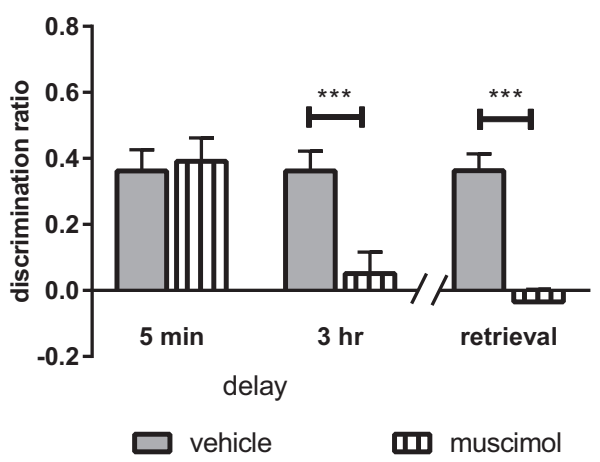

Figure 4. Activity in the NRe/Rh is required for both the encoding and retrieval of associative recognition memory. Infusion of the GABA receptor agonist muscimol into the NRe/Rh impaired performance in the object-in-place task when infusion occurred 15 min before the sample phase and memory was tested at a $3 \mathrm{~h}$ delay, but not when memory was tested after a 5 min delay. In addition, infusion of muscimol $15 \mathrm{~min}$ before the test phase impaired performance in the object-in-place task. Data are shown as mean \pm SEM. $n=12$. ${ }^{* * *} p<0.001$.

\section{Experiment 4: Cholinergic receptor transmission in the NRe is required for encoding but not retrieval of associative recognition memory}

The NRe contains a dense population of both nicotinic (Clarke et al., 1985) and muscarinic (Frey et al., 1985; Frey and Howland, 1992) cholinergic receptors, so to assess the importance of cholinergic neurotransmission in the NRe for object-in-place memory, the noncompetitive muscarinic receptor antagonist scopolamine or the nicotinic antagonist mecamylamine was infused before the sample or test phase. Memory performance was assessed after a $3 \mathrm{~h}$ delay.

Scopolamine impaired object-in-place performance when infused before the sample, but not before the test phase (Fig. $6 \mathrm{~A}$ ). Two-way ANOVA with drug and infusion timing as factors revealed a significant interaction $\left(F_{(1,22)}=10.50, p=0.004\right)$ and a significant main effect of drug $\left(F_{(1,22)}=10.87, p=0.003\right)$ and infusion timing $\left(F_{(1,22)}=7.455, p=0.012\right)$. Analysis of the simple main effects revealed a significant difference between the performance of the vehicle- and scopolamine-infused animals when infusions occurred before the sample phase only $(p<0.001)$. Further analysis confirmed that the vehicle-infused animals significantly discriminated between the moved and unmoved objects at both infusion time points (presample $t_{(11)}=5.04, p=$ 0.000 ; pretest $\left.t_{(11)}=7.39, p=0.000\right)$; in contrast, scopolamineinfused animals did not discriminate when the infusion occurred before the sample phase $\left(t_{(11)}=-0.26, p=0.797\right.$ n.s. $)$, but showed significant discrimination when the infusion occurred before the test phase $\left(t_{(11)}=5.02, p=0.000\right)$.

Infusion of mecamylamine impaired object-in-place performance when infused before the sample phase, but not before the test phase (Fig. 6B). Two-way ANOVA revealed a significant drug $X$ infusion timing interaction $\left(F_{(1,22)}=21.15, p=0.000\right)$ and significant main effects of drug $\left(F_{(1,22)}=20.36, p=0.000\right)$ and infusion timing $\left(F_{(1,22)}=13.13, p=0.002\right)$. Analysis of the simple main effects revealed a significant difference between the performance of the vehicle- and mecamylamine-infused animals when infusion occurred before the sample phase only $(p<0.001)$. Further analysis confirmed that the vehicle-infused animals showed significant discrimination between the moved and the unmoved objects under both infusion conditions (presample $t_{(11)}=5.30, p=0.000$; pretest $\left.t_{(11)}=7.19, p=0.000\right)$; in contrast, mecamylamine disrupted discrimination when administered presample $\left(t_{(11)}=-1.71, p=0.116\right.$ n.s. $)$, but not when administered pretest $\left(t_{(11)}=7.64, p=0.000\right)$.

Overall object exploration levels were not significantly altered by either scopolamine or mecamylamine (Table 3). Analysis of the total amount of object exploration in the sample phase revealed a nonsignificant drug $X$ infusion timing interaction after scopolamine $\left(F_{(1,22)}=1.07, p=0.312\right.$ n.s. $)$ or mecamylamine $\left(F_{(1,22)}=0.19, p=0.664\right.$ n.s. $)$ administration. Analysis of the total amount of object exploration completed in the test phase again revealed a nonsignificant drug $\times$ infusion timing interaction after scopolamine $\left(F_{(1,22)}=3.03, p=0.096\right.$ n.s. $)$ or mecamylamine $\left(F_{(1,22)}=0.32, p=0.576\right.$ n.s. $)$.

These results show that activation of both muscarinic and nicotinic cholinergic receptors in the NRe is essential for encoding, but not retrieval, of associative recognition memory.

\section{Experiment 5: Associative recognition memory depends on protein synthesis in the $\mathrm{NRe}$}

Given that the experiments revealed a time-dependent role for the NRe in object-in-place memory, we next investigated whether such long-term memory maintenance was dependent on protein synthesis. The protein synthesis inhibitor anisomycin was infused into the NRe before the sample phase and object-in-place recognition was tested after a 3 and 24 h delay. Memory performance at the two retention delays is shown in Figure 7A. Two-way ANOVA with drug and delay as factors revealed a significant interaction $\left(F_{(1,20)}=5.07, p=0.036\right)$ and significant main effects of both treatment $\left(F_{(1,20)}=13.42, p=0.002\right)$ and delay $\left(F_{(1,20)}=7.10\right.$, $p=0.015)$. Analysis of the simple main effects revealed that anisomycin treatment significantly impaired memory performance after the $24 \mathrm{~h}$ delay ( $p<0.001)$, but not the $3 \mathrm{~h}$ delay, and performance of the anisomycin-infused animals was significantly different at the 2 delays $(p<0.01)$. Further analysis confirmed that the vehicle-infused animals discriminated between the moved and unmoved objects at both delays tested $\left(3 \mathrm{~h}: t_{(10)}=\right.$ 4.50, $\left.p=0.001 ; 24 \mathrm{~h}: t_{(10)}=5.90, p=0.000\right)$; in contrast, anisomycin-infused animals did show significant discrimination at the 3 h delay $\left(t_{(10)}=2.99, p=0.014\right)$, but not at the $24 \mathrm{~h}$ delay $\left(t_{(10)}=-1.02, p=0.330\right.$ n.s. $)$. 
Table 2. Mean exploration times ( \pm SEM) in the sample and test phases of the object-in-place task after muscimol or AP5 infusions

\begin{tabular}{|c|c|c|c|c|c|c|}
\hline \multirow[b]{2}{*}{ Experiment } & \multirow[b]{2}{*}{ Delay } & \multirow[b]{2}{*}{ Condition } & \multirow{2}{*}{$\begin{array}{l}\text { Exploration in } \\
\text { sample phase (s) }\end{array}$} & \multicolumn{3}{|c|}{ Exploration in test phase (s) } \\
\hline & & & & Novel & Familiar & Total \\
\hline \multirow[t]{4}{*}{ Muscimol infused before sample phase } & \multirow[t]{2}{*}{$5 \min$} & Vehicle & $102.8 \pm 4.5$ & $24.6 \pm 2.3$ & $11.5 \pm 1.6$ & $36.1 \pm 3.1$ \\
\hline & & Muscimol & $86.3 \pm 8.3$ & $23.2 \pm 3.1$ & $9.5 \pm 1.6$ & $32.6 \pm 3.8$ \\
\hline & \multirow[t]{2}{*}{$3 \mathrm{~h}$} & Vehicle & $94.8 \pm 5.9$ & $32.0 \pm 2.6$ & $14.5 \pm 1.1$ & $46.4 \pm 2.5$ \\
\hline & & Muscimol & $97.8 \pm 5.0$ & $27.5 \pm 2.5$ & $25.0 \pm 2.2$ & $52.5 \pm 3.7$ \\
\hline \multirow[t]{2}{*}{ Muscimol infused before test phase } & \multirow[t]{2}{*}{$3 \mathrm{~h}$} & Vehicle & $89.4 \pm 3.8$ & $30.9 \pm 1.5$ & $14.9 \pm 1.4$ & $45.8 \pm 2.2$ \\
\hline & & Muscimol & $93.7 \pm 3.0$ & $22.4 \pm 2.3$ & $23.7 \pm 2.0$ & $46.0 \pm 3.8$ \\
\hline \multirow[t]{4}{*}{ AP5 infused before sample phase } & \multirow[t]{2}{*}{$3 \mathrm{~h}$} & Vehicle & $93.7 \pm 6.0$ & $28.4 \pm 2.0$ & $11.4 \pm 1.7$ & $39.9 \pm 2.7$ \\
\hline & & AP5 & $87.0 \pm 5.7$ & $26.1 \pm 2.4$ & $12.0 \pm 1.6$ & $38.1 \pm 3.7$ \\
\hline & \multirow[t]{2}{*}{$24 \mathrm{~h}$} & Vehicle & $93.5 \pm 2.9$ & $31.8 \pm 3.0$ & $12.4 \pm 1.2$ & $44.2 \pm 3.3$ \\
\hline & & AP5 & $94.3 \pm 4.2$ & $31.0 \pm 2.8$ & $14.2 \pm 1.1$ & $45.2 \pm 2.9$ \\
\hline
\end{tabular}

Exploration in the test phase is presented as mean time spent exploring the novel and familiar objects separately and as total exploration.

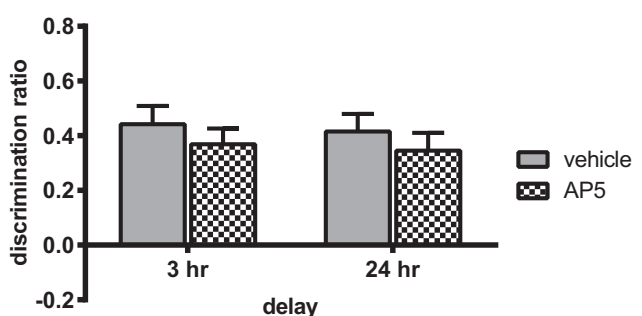

Figure 5. NMDAR activation in the NRe/Rh is not required for the encoding of associative recognition memory. Infusion of the NMDAR antagonist AP5 $(25 \mathrm{~mm} / \mathrm{site}) 15 \mathrm{~min}$ before the sample phase did not alter performance in the object-in-place task when memory was tested at either a $3 \mathrm{~h}$ or $24 \mathrm{~h}$ delay. Data are shown as mean \pm SEM. $n=12$.

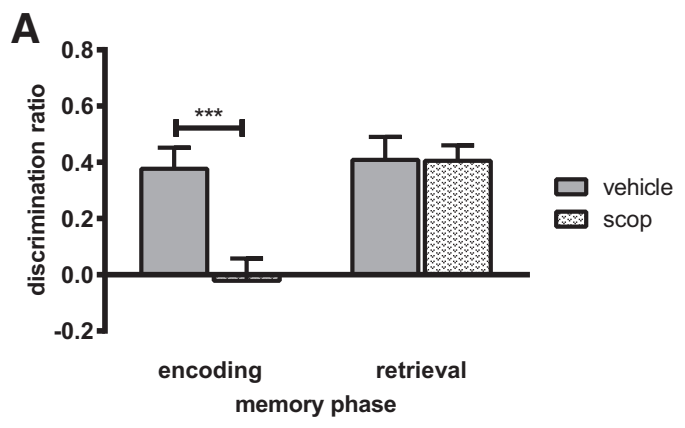

B

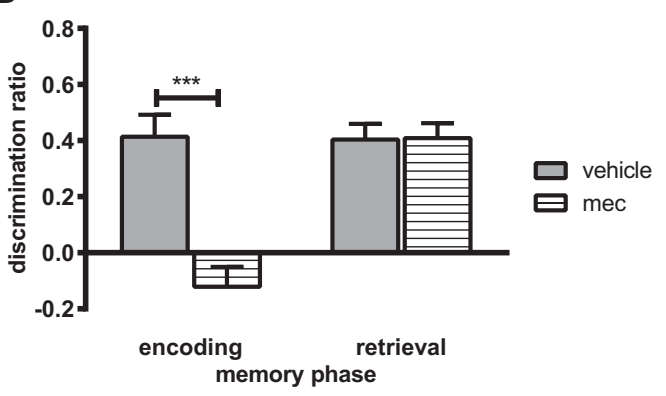

Figure 6. The encoding but not the retrieval of associative recognition memory requires the activation of nicotinic and muscarinic cholinergic receptors in the NRe/Rh. $\boldsymbol{A}$, Infusion of the muscarinic cholinergic receptor antagonist scopolamine. $\boldsymbol{B}$, Infusion of the nicotinic cholinergic receptor antagonist mecamylamine into the NRe/Rh impaired performance in the object-inplace task when infusion occurred 15 min before the sample phase but not when infusion occurred 15 min before the test phase. Data are shown as mean \pm SEM. $n=12$. ${ }^{* * *} p<0.001$.

Anisomycin is reported to cause apoptosis (Iordanov et al., 1997, 1998), so the experiment was repeated using the protein synthesis inhibitor actinomycin D. Analysis of the DR (Fig. 7B) revealed that actinomycin $\mathrm{D}$ significantly impaired object-in- place performance (mean DR vehicle $=0.49 \pm 0.08$; actinomycin $=-0.07 \pm 0.08)$, confirmed by a significant main effect of $\operatorname{drug}\left(F_{(1,9)}=22.13, p=0.001\right)$. The vehicle-infused animals discriminated between the moved and unmoved objects $\left(t_{(9)}=\right.$ 5.96, $p=0.000)$, whereas drug-treated animals did not $\left(t_{(9)}=\right.$ $-0.82, p=0.435$ n.s.).

Analysis of the total object exploration (Table 4) revealed that neither protein synthesis inhibitor infused before the sample phase had any effect on exploration (anisomycin drug $\times$ delay interaction: $F_{(1,20)}=0.17, p=0.681$ n.s.; main effect of drug: $F_{(1,20)}=1.61, p=0.219$ n.s.; main effect of delay: $F_{(1,20)}=0.09$, $p=0.767 \mathrm{~ns}$; actinomycin D: $F_{(1,9)}=0.13, p=0.727$ n.s. $)$.

Analysis of the total object exploration completed in the test phase after anisomycin revealed no effect of drug $\left(F_{(1,20)}=0.47\right.$, $p=0.500$ n.s.), delay $F_{(1,20)}=1.03, p=0.323$ n.s. $)$, or $\operatorname{drug} \times$ delay interaction $\left(F_{(1,20)}=4.27, p=0.052\right.$ n.s. $)$. Actinomycin D also had no effect on exploration during the test phase $\left(F_{(1,9)}=\right.$ $4.17, p=0.072$ n.s.).

These results show that long-term associative recognition memory is dependent on protein synthesis in the NRe.

\section{Discussion}

Permanent lesions in the ventral midline nuclei, the $\mathrm{NRe} / \mathrm{Rh}$, produced a delay-dependent impairment in object-in-place memory, but had no effect on novel object recognition or object location memory. Muscimol infusion specifically into NRe also had no effect on short-term memory, but when the retention delay was $3 \mathrm{~h}$, infusions before the sample or before the test phase impaired performance, indicating that both the encoding and retrieval phases of object-in-place memory are dependent on the NRe. Infusion of AP5 during the sample phase had no effect on memory performance; in contrast, both scopolamine and mecamylamine administered before the sample phase impaired performance after a $3 \mathrm{~h}$ delay; therefore, long-term object-in-place memory does not require NMDAR transmission, but is dependent on cholinergic receptor neurotransmission through both muscarinic and nicotinic receptors. Finally, inhibition of protein synthesis impaired memory performance after a $24 \mathrm{~h}$, but not $3 \mathrm{~h}$ delay, suggesting that the NRe participates in long-term objectin-place memory consolidation.

\section{NRe in an associative memory circuit}

The NRe plays a selective role in long-term object-in-place associative memory, as shown by performance deficits after both permanent and temporary inactivation. The latter finding not only confirms the delay-dependent role played by the NRe, but also allows us to exclude the possibility that intact short-term memory was due to the development of compensatory processes, such 
Table 3. Mean exploration times ( \pm SEM) in the sample and test phases of the object-in-place task after scopolamine or mecamylamine infusions

\begin{tabular}{|c|c|c|c|c|c|c|}
\hline \multirow[b]{2}{*}{ Infusate } & \multirow[b]{2}{*}{ Timing of infusion } & \multirow[b]{2}{*}{ Condition } & \multirow{2}{*}{$\begin{array}{l}\text { Exploration in } \\
\text { sample phase (s) }\end{array}$} & \multicolumn{3}{|c|}{ Exploration in test phase (s) } \\
\hline & & & & Novel & Familiar & Total \\
\hline \multirow[t]{4}{*}{ Scopolamine } & \multirow[t]{2}{*}{ Before sample phase } & Vehicle & $92.7 \pm 2.7$ & $21.3 \pm 2.1$ & $9.1 \pm 1.0$ & $30.5 \pm 2.1$ \\
\hline & & Scopolamine & $92.5 \pm 3.7$ & $17.7 \pm 1.5$ & $20.3 \pm 2.7$ & $38.1 \pm 3.6$ \\
\hline & \multirow[t]{2}{*}{ Before test phase } & Vehicle & $86.8 \pm 4.4$ & $29.2 \pm 3.1$ & $11.1 \pm 1.2$ & $40.3 \pm 3.2$ \\
\hline & & Scopolamine & $78.6 \pm 2.2$ & $25.2 \pm 2.0$ & $11.2 \pm 1.7$ & $36.5 \pm 3.1$ \\
\hline \multirow[t]{4}{*}{ Mecamylamine } & \multirow[t]{2}{*}{ Before sample phase } & Vehicle & $80.5 \pm 4.1$ & $19.6 \pm 2.5$ & $7.4 \pm 0.8$ & $27.0 \pm 2.4$ \\
\hline & & Mecamylamine & $79.6 \pm 5.6$ & $14.9 \pm 1.8$ & $17.9 \pm 1.5$ & $32.8 \pm 2.8$ \\
\hline & \multirow[t]{2}{*}{ Before test phase } & Vehicle & $84.3 \pm 2.3$ & $22.6 \pm 2.7$ & $8.6 \pm 0.5$ & $31.3 \pm 2.8$ \\
\hline & & Mecamylamine & $79.8 \pm 4.5$ & $23.4 \pm 2.0$ & $10.7 \pm 2.1$ & $34.1 \pm 3.7$ \\
\hline
\end{tabular}

Exploration in the test phase is presented as mean time spent exploring the novel and familiar objects separately and as total exploration.

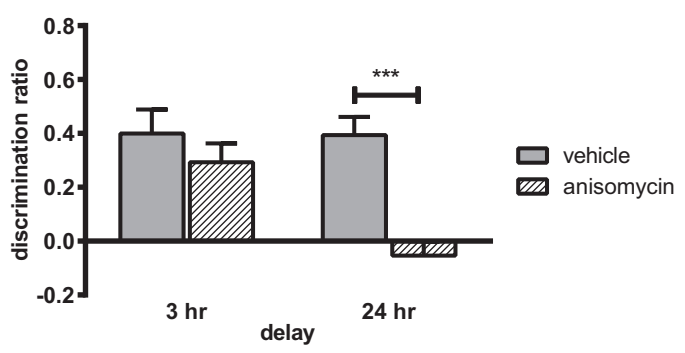

Figure 7. Protein synthesis in the NRe/Rh is required for the formation of associative recognition memory. Infusion of the protein synthesis inhibitor anisomycin into NRe/Rh before the sample phase impaired object-in-place memory performance when memory was tested at a $24 \mathrm{~h}$ delay but not a $3 \mathrm{~h}$ delay. Data are shown as mean \pm SEM. $n=11 .{ }^{* * *} p<0.001$.

Table 4. Mean exploration times ( \pm SEM) in the sample and test phases of the object-in-place task after anisomycin or actinomycin infusions

\begin{tabular}{|c|c|c|c|c|c|c|}
\hline \multirow[b]{2}{*}{ Infusate } & \multirow[b]{2}{*}{ Delay } & \multirow[b]{2}{*}{ Condition } & \multirow{2}{*}{$\begin{array}{l}\text { Exploration in } \\
\text { sample phase (s) }\end{array}$} & \multicolumn{3}{|c|}{ Exploration in test phase (s) } \\
\hline & & & & Novel & Familiar & Total \\
\hline \multirow[t]{4}{*}{ Anisomycin } & \multirow[t]{2}{*}{$3 \mathrm{~h}$} & Vehicle & $74.9 \pm 4.9$ & $23.6 \pm 2.7$ & $10.0 \pm 1.4$ & $33.6 \pm 3.4$ \\
\hline & & Anisomycin & $66.8 \pm 5.7$ & $16.9 \pm 2.3$ & $8.9 \pm 1.1$ & $25.8 \pm 3.0$ \\
\hline & \multirow[t]{2}{*}{$24 \mathrm{~h}$} & Vehicle & $71.0 \pm 6.1$ & $21.7 \pm 1.8$ & $9.5 \pm 1.3$ & $31.2 \pm 2.4$ \\
\hline & & Anisomycin & $66.9 \pm 3.4$ & $16.6 \pm 1.3$ & $18.5 \pm 1.5$ & $35.1 \pm 2.4$ \\
\hline \multirow[t]{2}{*}{ Actinomycin D } & \multirow[t]{2}{*}{$24 \mathrm{~h}$} & Vehicle & $81.2 \pm 4.4$ & $33.8 \pm 3.5$ & $11.4 \pm 2.2$ & $45.2 \pm 3.8$ \\
\hline & & Actinomycin D & $83.3 \pm 6.2$ & $25.0 \pm 2.1$ & $29.7 \pm 3.0$ & $54.7 \pm 2.3$ \\
\hline
\end{tabular}

Exploration in the test phase is presented as mean time spent exploring the novel and familiar objects separately and as total exploration.

as might occur through neural reorganization between surgery and behavioral testing.

Associative recognition is dependent on a neural circuit involving the HPC, mPFC, and PRH (Barker et al., 2007; Barker and Warburton, 2011), to which the NRe has bidirectional connections (Vertes et al., 2006). Patterns of neuronal activation in the NRe have been shown to have a direct influence on neurons in the HPC (Dolleman-Van der Weel et al., 1996, 2017), to which it provides an excitatory glutamatergic input (Dolleman-Van der Weel and Witter, 2000; Van der Werf et al., 2002; Vertes et al., 2006; Tomás Pereira et al., 2016); however, lesions in the NRe had no effect on the hippocampal-dependent object location memory task (Barker and Warburton, 2011). NRe lesions also had no effect on the perirhinal-dependent single item recognition memory task, so the object-in-place deficits are unlikely to reflect a loss of NRe input solely to either the HPC or PRH. The NRe provides a glutamatergic input to the mPFC (Di Prisco and Vertes, 2006; Eleore et al., 2011), but, although mPFC lesions impair object-inplace memory (Barker et al., 2007), other studies have suggested that NRe activity is not important for tasks that depend solely on the $\mathrm{mPFC}$, such as a visual serial reaction time task (Hembrook and Mair, 2011). There are, however, an increasing number of studies showing that that the NRe has a critical role in tasks for which cognitive demands require both HPC and $\mathrm{MPFC}$, possibly because the NRe provides a route of communication between these regions in the absence of a direct HPC-mPFC pathway or because the NRe can modulate activity in both regions simultaneously (Hoover and Vertes, 2012; Hallock et al., 2016). The impairments in object-in-place memory observed in the present study may be explained by either of these suggestions, although, because HPC-mPFC communication is required for object-inplace performance at both short- and long-term retention delays (Barker and Warburton, 2008) but here memory impairments were only seen at the $3 \mathrm{~h}$ delay, it is unlikely that the NRe acts as a simple relay station between the HPC and mPFC. Although previous studies have also reported a delay-dependent deficits after NRe lesions (Loureiro et al., 2012), arguing that this effect is a result of an increased requirement for HPC-mPFC cross talk at longer delays, these tasks investigated spatial working memory and thus used considerably shorter delays than those used here. Therefore, the available evidence points to an important role for the NRe in coordinating activity between the mPFC and HPC (Hallock et al., 2016), but the mPFC and HPC also each interact with the PRH during associative recognition memory formation. Given the reciprocal connections between the NRe and PRH (Agster et al., 2016; Pereira et al., 2016), the NRe could be critical for coordinating activity between all three brain regions and, at present, there is no direct evidence to either support or refute this possibility.

Infusion of muscimol before either the sample phase or test phase impaired long-term object-in-place, showing that the NRe supports both encoding and retrieval. Reports of the effects of muscimol, albeit at higher volumes and concentrations than used in the present study, suggest that neuronal suppression can last several hours after an infusion (Arikan et al., 2002; van Duuren et al., 2007). Therefore, it is possible that, after the presample infusion of muscimol in the present study, some NRe tissue remains inactive during the test phase. Evidence suggests, however, that after a $3 \mathrm{~h}$ delay, only a small proportion of neurons close to the infusion site will still be affected (Arikan et al., 2002) and so are unlikely to account for the significant deficits observed.

Electrophysiological recording studies have shown that encoding of object-place associative information requires the flow of information from the HPC to the mPFC (Place et al., 2016), whereas retrieval requires $\mathrm{mPFC}$ to HPC information trnasfer (Place et al., 2016) via the NRe (Hallock et al., 2016;). The NRe maintains the specificity of memory information processing through modulation of both HPC and mPFC activity (DollemanVan der Weel et al., 2009; Ito et al., 2015), but in these studies, the pattern of NRe activity during the behavioral tasks was found to be independent of memory requirements, suggesting that the NRe itself does not process memory information. Although our observation that NMDAR blockade in the NRe had no effect on 
memory whereas such blockade in the HPC or mPFC produced significant impairments (Barker and Warburton, 2008) is somewhat consistent with the view that the NRe does not process mnemonic information, our results that the maintenance of object-in-place associative memory was dependent on protein synthesis does suggest that the NRe is involved in object-in-place memory consolidation and stablization (Pereira de Vasconcelos and Cassel, 2015). Whether the synthesis of new proteins occurs in the cortical- or hippocampal-projecting NRe cells or in a third cell population remains to be established.

Cholinergic-receptor-mediated neurotransmission in the NRe was found to be critical for object-in-place memory, but whereas this region contains both nicotinic (Clarke et al., 1985) and muscarinic receptors (Wamsley et al., 1984; Cortés and Palacios, 1986; Mash and Potter, 1986), their precise distribution has yet to be described. The cholinergic input to the NRe arises from the pedunculopontine (PPT) and laterodorsal tegmental nuclei (Woolf and Butcher, 1986; Cornwall et al., 1990), so its cholinergic innervation is clearly distinct from that of the HPC or PFC, which arises in the basal forebrain. Salient environmental stimuli increase PPT cholinergic neuron firing, which in turn results in a depolarization of thalamocortical neurons (McCormick and Bal, 1997; Steriade et al., 1997, 2004) via both nicotinic and muscarinic receptors. Cholinergic input to the thalamic nuclei may provide an important alternative route by which hippocampal or cortical function may be modulated during memory formation, but further experiments are clearly necessary to establish how precisely this is achieved.

It has been argued that, through its projections to the $\mathrm{mPFC}$ and HPC, the NRe can regulate attentional vigilance and cortical arousal (Steriade et al., 1990, 1997; Van der Werf et al., 2002; Vertes et al., 2007). In the present study, no changes in general exploratory activity were found and the memory impairments were specific; that is, there were no deficits in the novel object recognition or object location tasks. Therefore, it is unlikely that the object-in-place memory impairments after NRe inactivation or blockade of cholinergic neurotransmission are explained by nonspecific changes in arousal or attention. Rather, the results indicate a role for NRe in regulating HPC-mPFC interactions under conditions of greater mnemonic demand, possibly by stabilizing memory traces within the network.

The NRe can now be incorporated as a key node within a recognition memory network that includes the HPC, mPFC, and $\mathrm{PRH}$, although its role is selectively in long-term memory formation and retrieval. These results, together with the existing literature, suggest that the NRe coordinates activity across HPC and mPFC, although the mechanism by which this is achieved may depend on the stages of memory processing. Indeed, the NRe is likely to play a diverse role and the delay dependence of its involvement argues strongly against a model of a simple relay between the subcortical and cortical structures. Rather, the data suggest that the NRe is an important facilitator of HPC-mPFC interactions and that, within the NRe, encoding of mnemonic information is mediated by cholinergic neurotransmission. Longterm associative memory stability within the network is clearly mediated by a protein-synthesis-dependent mechanism. Although the NRe must be included within the associative recognition memory circuit, it is now necessary to conduct detailed investigations of the direction of information transfer among the mPFC, HPC, and NRe to establish the mechanism by which NRe provides important regulation of long-term memory processing.

\section{References}

Agster KL, Tomás Pereira I, Saddoris MP, Burwell RD (2016) Subcortical connections of the perirhinal, postrhinal, and entorhinal cortices of the rat. II. Efferents. Hippocampus 26:1213-1230. CrossRef Medline

Albasser MM, Poirier GL, Aggleton JP (2010) Qualitatively different modes of perirhinal-hippocampal engagement when rats explore novel vs. familiar objects as revealed by c-fos imaging. Eur J Neurosci 31:134-147. CrossRef Medline

Arikan R, Blake NM, Erinjeri JP, Woolsey TA, Giraud L, Highstein SM (2002) A method to measure the effective spread of focally injected muscimol into the central nervous with electrophysiology and light microscopy. J Neurosci Methods 118:51-57. CrossRef Medline

Bachevalier J, Nemanic S (2008) Memory for spatial location and objectplace associations are differentially processed by the hippocampal formation, parahippocampal areas TH/TF and perirhinal cortex. Hippocampus 18:64-80. CrossRef Medline

Barker GR, Warburton EC (2008) NMDA receptor plasticity in the perirhinal and prefrontal cortices is crucial for the acquisition of long-term object-in-place associative memory. J Neurosci 28:2837-2844. CrossRef Medline

Barker GR, Warburton EC (2011) When is the hippocampus involved in recognition memory? J Neurosci 31:10721-10731. CrossRef Medline

Barker GR, Bird F, Alexander V, Warburton EC (2007) Recognition memory for objects, place and temporal order: a disconnection analysis of the role of the medial prefrontal cortex and perirhinal cortex. J Neurosci 27:2948-2957. CrossRef Medline

Barker GR, Banks PJ, Scott H, Ralph GS, Mitrophanous KA, Wong LF, Bashir ZI, Uney JB, Warburton EC (2017) Separate elements of episodic memory subserved by distinct hippocampal-prefrontal connections. Nat Neurosci 20:242-250. CrossRef Medline

Brincat SL, Miller EK (2015) Frequency specific hippocampal-prefrontal interactions during associative learning. Nat Neurosci 18:576-581. CrossRef Medline

Browning PG, Easton A, Buckley MJ, Gaffan D (2005) The role of prefrontal cortex in object-in-place learning in monkeys. Eur J Neurosci 22:32813291. CrossRef Medline

Bussey TJ, Muir JL, Aggleton JP (1999) Functionally dissociating aspects of event memory: the effects of combined perirhinal and postrhinal cortex lesions on object and place memory in the rat. J Neurosci 19:495-502. Medline

Bussey TJ, Dias R, Amin E, Muir JL, Aggleton JP (2001) Perirhinal cortex and place-object conditional learning in the rat. Behav Neurosci 115:776785. CrossRef Medline

Cholvin T, Loureiro M, Cassel R, Cosquer B, Geiger K, De Sa Nogueira D, Raingard H, Robelin L, Kelche C, Pereira de Vasconcelos A, Cassel JC (2013) The ventral midline thalamus contributes to strategy shifting in a memory task requiring both prefrontal cortical and hippocampal functions. J Neurosci 33:8772-8783. CrossRef Medline

Clarke PB, Schwartz RD, Paul SM, Pert CB, Pert A (1985) Nicotinic binding in rat brain: autoradiographic comparison of $[3 \mathrm{H}]$ acetylcholine, $[3 \mathrm{H}]$ nicotine, and ['125l']-alpha-bungarotoxin1. J Neurosci 5:1307-1315. Medline

Cornwall J, Cooper JD, Phillipson OT (1990) Afferent and efferent connections of the laterodorsal tegmental nucleus in the rat. Brain Res Bull 25:271-284. Medline

Cortés R, Palacios JM (1986) Muscarinic cholinergic receptor subtypes in the rat brain. I. Quantitative autoradiographic studies. Brain Res 362:227238. CrossRef Medline

Diana RA, Yonelinas AP, Ranganath C (2007) Imaging recollection and familiarity in the medial temporal lobe: a three-component model. Trends Cogn Sci 11:379-386. CrossRef Medline

Di Prisco GV, Vertes RP (2006) Excitatory actions of the ventral midline thalamus (rhomboid/reuniens) on the medial prefrontal cortex in the rat. Synapse 60:45-55. CrossRef Medline

Dix SL, Aggleton JP (1999) Extending the spontaneous preference test of recognition: evidence of object-location and object-context recognition. Behav Brain Res 99:191-200. CrossRef Medline

Dolleman-Van der Weel MJ, Witter MP (1996) Projections from the reuniens nucleus thalami to the entorhinal cortex, hippocampal field CA1, and the subiculum in the rat arise from different populations of neurons. J Comp Neurol 364:637-650. CrossRef Medline

Dolleman-Van der Weel MJ, Witter MP (2000) Nucleus reuniens thalami 
innervates gamma aminobutyric acid positive cells in hippocampal field CA1 of the rat. Neurosci Lett 278:145-148. CrossRef Medline

Dolleman-Van der Weel MJ, Morris RG, Witter MP (2009) Neurotoxic lesions of the thalamic reuniens or mediodorsal nucleus in rats affect non-mnemonic aspects of watermaze learning. Brain Struct Funct 213: 329-342. CrossRef Medline

Dolleman-Van der Weel MJ, Lopes da Silva FH, Witter MP (2017) Interaction of nucleus reuniens and entorhinal cortex projections in hippocampal field CA1 of the rat. Brain Struct Funct 222:2421-2438. CrossRef Medline

Eleore L, López-Ramos JC, Guerra-Narbona R, Delgado-García JM (2011) Role of reuniens nucleus projections to the medial prefrontal cortex and to the hippocampal pyramidal CA1 area in associative learning. PLoS One 6:e23538. CrossRef Medline

Ennaceur A, Delacour J (1988) A new one-trial test for neurobiological studies of memory in rats. 1: behavioral data. Behav Brain Res 31:47-59. CrossRef Medline

Ennaceur A, Neave N, Aggleton JP (1996) Neurotoxic lesions of the perirhinal cortex do not mimic the behavioural effects of fornix transection in the rat. Behav Brain Res 80:9-25. CrossRef Medline

Frey KA, Howland MM (1992) Quantitative autoradiography of muscarinic cholinergic receptor binding in the rat brain: distinction of receptor subtypes in antagonist competition assays. J Pharmacol Exp Ther 263:13911400. Medline

Frey KA, Ehrenkaufer RL, Agranoff BW (1985) Quantitative in vivo receptor binding II. Autoradiographic imaging of muscarinic cholinergic receptors. J Neurosci 5:2407-2414. Medline

Hallock HL, Wang A, Griffin AL (2016) Ventral midline thalamus is critical for hippocampal prefrontal synchrony and spatial working memory. J Neurosci 36:8372-8389. CrossRef Medline

Hembrook JR, Mair RG (2011) Lesions of reuniens and rhomboid thalamic nuclei impair radial maze win-shift performance. Hippocampus 21:815826. CrossRef Medline

Hembrook JR, Onos KD, Mair RG (2012) Inactivation of ventral midline thalamus produces selectve spatial delayed conditional discrimination impairment in the rat. Hippocampus 22:853-860. CrossRef Medline

Herkenham M (1978) The connections of the reuniens nucleus thalamus: evidence for a direct thalamo-hippocampal pathway in the rat. J Comp Neurol 177:589-610. CrossRef Medline

Hoover WB, Vertes RP (2012) Collateral projections from reuniens nucleus of thalamus to hippocampus and medial prefrontal cortex in the rat: a single and double retrograde fluorescent labelling study. Brain Struct Funct 217:191-209. CrossRef Medline

Iordanov MS, Pribnow D, Magun JL, Dinh TH, Pearson JA, Chen SL, Magun BE (1997) Ribotoxic stress response: activation of the stress-activated protein kinase JNK1 by inhibitors of the peptidyl transferase reaction and by sequence-specific RNA damage to the alpha-sarcin/ricin loop in the 28 rRNA. Mol Cell Biol 17:3373-3381. CrossRef Medline

Iordanov MS, Pribnow D, Magun JL, Dinh TH, Pearson JA, Magun BE (1998) Ultraviolet radiation triggers the ribotoxic stress response in mammalian cells. J Biol Chem 273:15794-15803. CrossRef Medline

Ito HT, Zhang SJ, Witter MP, Moser EI, Moser MB (2015) A prefrontal thalamo-hippocampal circuit for goal directed spatial navigation. Nature 522:50-55. CrossRef Medline

Kesner RP, Ragozzino ME (2003) The role of the prefrontal cortex in objectplace learning: a test of the attribute specificity model. Behav Brain Res 146:159-165. CrossRef Medline

Kim H (2011) Neural activity that predicts subsequent memory and forgetting: a meta-analysis of $74 \mathrm{fMRI}$ studies. Neuroimage 54:2446-2461. CrossRef Medline

Kim H (2013) Differential neural activity in the recognition of old versus new events: an activation likelihood estimation meta-analysis. Hum Brain Mapp 34:814-836. CrossRef Medline

Loureiro M, Cholvin T, Lopez J, Merienne N, Latreche A, Cosquer B, Geiger K, Kelche C, Cassel JC, Pereira de Vasconcelos A (2012) The ventral midline thalamus (reuniens and rhomboid nuclei) contributes to the persistence of spatial memory in rats. J Neurosci 32:9947-9959. CrossRef Medline

Mash DC, Potter LT (1986) Autoradiographic localization of $\mathrm{m} 1$ and $\mathrm{m} 2$ muscarinic receptors in the rat-brain. Neuroscience 19:551-564. CrossRef Medline

McCormick DA, Bal T (1997) Sleep and arousal: thalamocortical mechanisms. Annu Rev Neurosci 20:185-215. CrossRef Medline

Pereira de Vasconcelos A, Cassel JC (2015) The nonspecific thalamus: a place in a wedding bed for making memories last? Neurosci Biobehav Rev 54:175-196. CrossRef Medline

Tomás Pereira I, Agster KL, Burwell RD (2016) Subcortical connections of the perirhinal, postrhinal, and entorhinal cortices of the rat. I. Afferents. Hippocampus 26:1189-1212. CrossRef Medline

Place R, Farovik A, Brockmann M, Eichenbaum H (2016) Bidirectional prefrontal-hippocampal interaction support context guided memory. Nat Neurosci 19:992-994. CrossRef Medline

Steriade M (2004) Acetylcholine systems and rhythmic activities during the waking-sleep cycle. Prog Brain Res 145:179-196. CrossRef Medline

Steriade M, Datta S, Paré D, Oakson G, Curró Dossi RC (1990) Neuronal activities in brain-stem cholinergic nuclei related to tonic activation processes in thalamocortical systems. J Neurosci 10:2541-2559. Medline

Steriade M, Jones EG, McCormick DA (1997) Thalamic, organization and chemical neuroanatomy. Thalamus 1:269-338.

Swanson LW (1998) Brain maps: structure of the rat brain. Amsterdam, the Netherlands: Elsevier.

Van der Werf YD, Witter MP, Groenewegen HJ (2002) The intralaminar and midline nuclei of the thalamus: Anatomical and functional evidence for participation in processes of arousal and awareness. Brain Res Rev 39:107-140. CrossRef Medline

van Duuren E, van der Plasse G, van der Blom R, Joosten RN, Mulder AB, Pennartz MA, Feenstra MG (2007) Pharmacological manipulation of neuronal ensemble activity by reverse microdialysis in freely moving rats: a comparative study of the effects of tetrodotoxin, lidocaine and muscimol. J Pharmacol Exp Ther 323:61-69. CrossRef Medline

Vertes RP (2002) Analysis of the projections from the medial prefrontal to the thalamus in the rat with emphasis on nucleus reuniens. J Comp Neurol 442:163-187. CrossRef Medline

Vertes RP, Hoover WB, Do Valle AC, Sherman A, Rodriguez JJ (2006) Efferent projections of the reuniens and rhomboid nuclei of the thalamus in the rat. J Comp Neurol 499:768-796. CrossRef Medline

Vertes RP, Hoover WB, Szigeti-Buck K, Leranth C (2007) Nucleus reuniens of the midline thalamus: link between the medial prefrontal cortex and the hippocampus. Brain Res Bull 71:601-609. CrossRef Medline

Wamsley JK, Zarbin MA, Kuhar MJ (1984) Distribution of muscarinic cholinergic high and low affinity agonist binding sites: a light microscopic autoradiographic study. Brain Res Bull 12:233-243. CrossRef Medline

Wan H, Aggleton JP, Brown MW (1999) Different contributions of the hippocampus and perirhinal cortex to recognition memory. J Neurosci 19: 1142-1148. Medline

Woolf NJ, Butcher LL (1986) Cholinergic systems in the rat brain: III. projections from the pontomesencephalic tegmentum to the thalamus, tectum, basal ganglia, and basal forebrain. Brain Res Bull 16:603-637. CrossRef Medline

Wouterlood FG, Saldana E, Witter MP (1990) Projection from the nucleus reuniens thalami to the hippocampal region: light and electron microscopic tracing study in the rat with the anterograde tracer phaseolus vulgarisleucoagglutinin. J Comp Neurol 296:179-203. CrossRef Medline 